\title{
INTRODUCCIÓN AL PENSAMIENTO LINGÜíSTICO DE JUAN ANDRÉS
}

\author{
Maria Dolores Abascal \\ Universidad de Alicante \\ lolav@ua.es
}

\begin{abstract}
Resumen
El jesuița español Juan Andrés dejó su país cuando fue expulsada la Compañía de Jesús, y desarrolló después, en Italia, una importante labor intelectual. Origen, progresos y estado actual de toda la literatura (1782-1799), la primera historia universal de las letras y las ciencias, es el exponente más interesante de esa actividad; se trata de un extenso trabajo enciclopédico, historiográfico y ensayístico, que fue admirado en Europa a finales del siglo XVIII, y que incluye una parte dedicada a la Gramática. Este artículo trata de las ideas de Andrés sobre la Gramática y sobre la historia de los estudios lingüísticos.

PALABRAS CLAVE: Gramática, Lingüistica, Historiografia, Filologia, Juan Andrés.
\end{abstract}

\begin{abstract}
The Spanish jesuit Juan Andrés left his country when the Society of Jesus was expelled and, afterwards, he developed an important intellectual activity in Italy. Origen, progresos y estado actual de toda la literatura (1782-1799), the first Letters and Sciences universal history, is the most interesting exponent of that activity; it is an extensive, encyclopaedic, historiographic and essayistic work, admired in Europe at the end of the eighteenth century, and it includes a section on Grammar. This paper deals with Andres's ideas about Grammar and about the History of Linguistics Studies.
\end{abstract}

KEY WORDS: Grammar, Linguistics, Historiography, Philology, Juan Andrés.

La biografía de Juan Andrés (Planes 1740-Roma 1817) y su contribución al saber muestran un evidente paralelismo con las de Hervás y Panduro, aunque la figura de Andrés resulte hoy bastante más desconocida en el ámbito de la Lingüistica. Ambos son jesuitas españoles que dejan el país como consecuencia del decreto de expulsión de su orden en 1767 , acrecientan en el exilio su labor intelectual y construyen obras relevantes de vocación abarcadora y totalizante. Juan Andrés era, cuando le llega la expulsión, catedrático de retórica y poesía en la Universidad de Gandía, fundada y dirigida por la Compañía de Jesús; de allí pasó a Italia (Córcega, Ferrara, más de veinte años en Mantua y luego Nápoles y Roma, entre otros lugares), y allí acabó siendo un intelectual prestigiado: un miembro de diversas Academias de Ciencias y Letras que maneja manuscritos y catálogos de importantes bibliotecas e impulsa él mismo nuevas catalogaciones, que observa de cerca el estado de la cultura de su tiempo y participa con autoridad en sus debates, y que escribe, entre otras cosas, Origen, progreso y estado actual de toda la literatura, la primera historia universal de las Letras y las Ciencias'. Esa extensa obra enciclopédica, escrita en italiano y publicada en Parma, en siete volúmenes editados entre 1782 y $1799^{2}$, es una construcción historiográfica

1 Andrés, J.: Origen, progresos y estado actual de toda la literatura, ed. de Jesús García Gabaldón, Santiago Navarro y Carmen Valcárcel, dir. Pedro Aullón de Haro. Madrid, Verbum, 1997-2002, 6 vols.

2 En 1822 Andrés añade un tomo de ampliación. La traducción al español, realizada por Carlos Andrés, hermano del autor, se publica en diez tomos, en la imprenta de Sancha, desde 1784 hasta 1806. 
de carácter ensayístico y crítico, en la que, entendiéndose la literatura en el sentido más general del término (como todo lo escrito que resulta relevante culturalmente), y adoptando una perspectiva universalista, evolucionista, comparatista y hermenéutica, se exponen los pasos seguidos en las distintas áreas de la cultura desde su decantación original hasta el estado alcanzado a finales del siglo XVIII.

La reciente edición crítica de esta magna obra, además de hacer justicia a una contribución a la cultura europea que no merece ser olvidada ${ }^{3}$, ha acercado a los investigadores de la Historiografía lingüística un texto significativo para el estudio del devenir de las ideas en esta materia. Este artículo quiere ser una primera aproximación al análisis del pensamiento lingüístico de este erudito, por lo que expondré sobre todo las ideas que muestra Andrés acerca de la gramática y su historia en la parte dedicada a esta área del saber y me limitaré a dejar constancia de otros aspectos de su reflexión sobre el lenguaje y su estudio que se pueden reconstruir en el conjunto de la obra.

\section{La reflexión sobre el lenguaje en Origen, progresos y estado actual de toda la litera- tura}

Para entender cabalmente el discurso de Andrés acerca del lenguaje y de los estudios lingüísticos, parece obligado considerar primeramente cuál es el lugar que asigna en su obra a esta parcela y cuál es el tratamiento general que le aplica. Esto exige una referencia previa a la organización del conjunto de la obra.

En esa organización general cabe destacar la utilización de dos ejes: el temático o de materias y el diacrónico. El primero, habitual en una enciclopedia, corresponde a la decisión de tratar separadamente las distintas materias que conforman la literatura, y exige una clasificación de éstas; el segundo es el propio de la historiografía, inevitable en una obra que trata del origen, los progresos y el estado actual de la cultura escrita. Andrés conjuga ambos.

La división de la literatura en partes se observa, desde luego, en la distribución de la materia en los siete volúmenes y en los índices de éstos, pero, además, es comentada y justificada por el autor en el prefacio general de la obra. Andrés explica en esta presentación que ha considerado las ideas expuestas por Francis Bacon en Novum Organum (1620) y la clasificación que, siguiendo a éste, realizan D'Alembert y Diderot en la Enciclopedia ${ }^{4}$, un referente que es, en todo, ineludible para Andrés, tanto por la repercusión política y cultural de la obra de los franceses como por ser un precedente muy cercano de la suya, lo que con-

\footnotetext{
3 Se ha señalado el tremendo contraste entre el reconocimiento que obtuvo Andrés en su tiempo (cuando gozó del amparo de varios monarcas europeos y Herder y Goethe, en sus viajes a Italia, se desplazaban a Mantua con la intención de visitarle) y el posterior olvido de su obra. Respecto a la dimensión europea de la obra de Andrés, hay que decir que ésta se observa tanto en la recepción que tuvo como en su propia configuración, porque su exposición se refiere a la elaboración cultural en el conjunto de los territorios europeos e incluso al contraste de ésta con la aportación conocida de otras culturas como la árabe o la china. De ahí su carácter de historia universal de la literatura ya señalado por Menéndez Pelayo. Véase para estas cuestiones el "Estudio preliminar" de la edición citada.
}

4 Diderot y D'Alembert (1756): Encyclopédie, ou dictionnaire raisonné, des Arts et des Métiers, ed. facsímil. Milán/ París, Franco Maria Ricci ed., 1978. 
vierte a aquélla en el fondo sobre el cual edifica el jesuita ${ }^{5}$. Los enciclopedistas, igual que Bacon, habían distinguido en la literatura tres grandes bloques vinculados a tres potencias del alma: la Historia (que se relaciona con la memoria), la Poesía (relacionada con la imaginación) y la Filosofía (que se relaciona con la razón y que incluye todas las materias no contenidas en las dos primeras). Pero Andrés considera que esa clasificación, aunque pueda resultar adecuada a fin de examinar la genealogía de las ciencias, no sirve para dar cuenta de su historia, porque separa sectores que muestran en su desarrollo alguna cercanía. Y aduce, precisamente, entre otros ejemplos, el de la Gramática: ésta, dice, forma parte, en su génesis, de la Filosofía (lo que llevaría a situarla entre las ciencias que se han desarrollado a partir de ella), pero su relación con la Poesía y la Elocuencia aconseja tratarla en el bloque dedicado a estos otros sectores.

Atendiendo a esos problemas y considerando que no necesita una división muy exacta, anuncia que él distinguirá dos grandes clases de escritos, las Buenas Letras y las Ciencias; que dentro de las Ciencias distinguirá las Naturales y las Eclesiásticas; y que dentro de las Buenas Letras incluirá la Poesía, la Elocuencia, la Historia y “todos los estudios filológicos" (la clasificación completa de las materias y el modo en que las agrupa puede verse en el cuadro que se adjunta como anexo I). Hay que advertir ya que el uso de la expresión "todos los estudios filológicos" en la presentación de su plan resulta muy significativo, porque en ningún otro caso opta por una expresión tan vaga para sustituir un término bien acunado por la tradición como es el de Gramática. El nombre de la disciplina gramatical se usará sin reservas en adelante, en cualquier lugar, incluyendo, por supuesto, el título de la parte dedicada a esa área del saber, pero la opción por la denominación más genérica que observamos en el Prefacio muestra indirectamente la concepción que tiene Andrés de este saber y muestra también un cierto estado de la disciplina. A ello me referiré enseguida.

En lo que se refiere al otro aspecto organizativo, el de la conjunción de lo diacrónico y lo temático, el autor advierte también en el Prefacio que ha resuelto elaborar un primer volumen de eje únicamente histórico en el que, sin dividir todavía en áreas o ramas la producción cultural, expone aspectos significativos de todas ellas, en un recorrido por diversos momentos o etapas de la historia de la cultura (véase el índice general de este volumen en el anexo II). Y anticipa en esa primera entrega el material que se examinará con mayor detenimiento y especificidad en tomos sucesivos, ya dedicados separadamente a las diferentes ramas del arte y el saber. Pero también en los tomos de tratamiento específico de las diferentes materias, que constituyen el grueso de la obra, persiste el eje diacrónico, en cuanto que en ellos se analiza separadamente el desarrollo histórico de cada sector, desde su decantación originaria hasta el presente, incluyendo una mención a los adelantamientos que deberían realizarse para acercarse a la perfección deseable.

En el contexto de esas decisiones sobre el orden general de la obra, cabe concretar ya el modo en que se inserta en ella la Gramática: las Buenas Letras ocupan los volúmenes II y

\footnotetext{
5 De hecho, la obra de Andrés puede entenderse, en algún sentido, como contestación a la francesa. Los enciclopedistas habían planteado en su Prospecto de la Enciclopedia, de 1751, la imposibilidad de acometer un solo hombre una obra de esta envergadura, pero Andrés lo hace; habian optado por el formato de diccionario enciclopédico, y él hace una historia crítica; habian conformado un compendio del saber laico, enfrentado al dominio cultural de la cultura religiosa, mientras Andrés reúne por primera vez en una obra de estas características las Ciencias Eclesiásticas y les otorga un lugar en el contexto de una cultura racional.
} 
III, y dentro de éstas, se dedica el volumen II a la Poesía (libro primero) y el volumen III, a la Elocuencia (libro segundo), la Historia (libro tercero) y la Gramática (libro cuarto). La Gramática es, por tanto, el libro cuarto de las Buenas Letras, y se sitúa como última parte del volumen III. Tiene una extensión de 55 páginas en la edición actual ${ }^{6}$, y está dividida en cinco capítulos:

\section{De la Gramática en general \\ II. Gramática técnica \\ III. Exegética \\ IV. Crítica \\ V. Conclusión}

En estos capítulos se realizan dos repasos históricos relacionados con la materia que nos ocupa: el que aparece en el primer capítulo ("De la gramática general"), que es una historia de todos los estudios filológicos (porque Andrés hace equivaler aquí Gramática general a Filología), y el que aparece en el segundo capítulo ("De la gramática técnica"), que recoge sólo las obras de carácter más lingüístico, y no las de exégesis y crítica (que hoy situaríamos en el marco de los estudios literarios), a las que se refieren los dos capítulos siguientes. Además, se encuentran algunas referencias a la gramática (y a otros aspectos del lenguaje) en el primer volumen (el que se articula siguiendo las grandes etapas de la cultura) y, de manera más limitada y aislada, en otros lugares de la obra.

El predominio de lo histórico hace que en la obra de Andrés encontremos, sobre todo, una historia de la gramática (o, más bien, una historia de los estudios lingüísticos o de la Lingüística). Pero, evidentemente, al construir esa historia el autor selecciona, y enfatiza o pasa por alto, las distintas contribuciones (porque su obra es declaradamente crítica y no meramente expositiva), lo que nos permite observar también cómo concibe la gramática este erudito de formación clásica jesuítica en un momento de gran interés en la evolución de ésta y otras disciplinas. A estas dos vertientes me refiero a continuación: a su concepción de la gramática y a la historia de ésta que construye.

\section{El concepto de Gramática}

La primera constatación es que Andrés maneja el concepto de gramática atribuyéndole dos significados, uno más abarcador que otro. En su significado más abarcador entiende la gramática como filologia. Ese valor se otorga al término en el Prefacio del tomo II, al presentar la parte de su obra dedicada a las Buenas Letras y las materias que en ella son tratadas:

La Gramática, cultivada con la doctrina y erudición que le dieron los antiguos y los celebrados gramáticos de los felices tiempos del restablecimiento de nuestra literatura, no es materia tan limitada como comúnmente se cree, y comprende la Crítica, la Hermenéutica y toda suerte de estudios filológicos y eruditos (Andrés: II, 19).

6 La extensión que ocupan las diferentes materias es variable: el volumen de la Poesía tiene 409 páginas, la Elocuencia ocupa más de doscientas y la Historia casi doscientas cincuenta (aunque incluye, además de la Historia en sentido estricto, la Geografia, la Cronología y la Anticuaria). Andrés dice que ninguna materia gusta a los lectores tanto como la poesía y que pocos tienen interés en los gramáticos (Andrés: II, 18). 
Esa presentación de la materia permite también observar que tal concepción de la gramática no era la única en su tiempo, e incluso que no era ya la dominante ("no es materia tan limitada como comúnmente se cree") y que Andrés mantiene la concepción antigua que había sido restaurada y prolongada por los humanistas del Renacimiento.

La misma filiación, su inserción en el mundo clásico, se hace explícita de nuevo al comienzo del libro dedicado a la Gramática, cuando Andrés declara que se vale de la voz de Quintiliano para presentar las tres partes que reconocían en ella los antiguos y que él va a considerar: la metódica o técnica (que "enseñaba el método y prescribía las leyes del buen modo de escribir y de hablar"); la histórica o exegética (que "se empleaba en la explicación de los escritores"); y la crítica ("nueva rama que se añadía a las otras dos" y se ocupa de "enmendar los escritos y formar juicio de su autenticidad") (Andrés: III, 478). Esa división es la que traslada a la organización del libro en capítulos que se ha señalado (I. De la Gramática en general; II. Gramática técnica; III. Exegética; IV. Crítica; y V. Conclusión), y en ella se observa ya el segundo significado, el más restringido, que maneja Andrés en su concepción de la disciplina, el de la gramática entendida como gramática técnica.

Utilizado el término en uno u otro sentido, cabe hablar de una concepción antigua. Es sabido que la elaboración de un saber gramatical, aunque se inicia en el marco de la Filosofía al hilo de una reflexión sobre características esenciales del lenguaje (naturaleza o convención; analogía o anomalía...), se desarrolla y consolida como Filología, es decir, como arte de lectura, análisis, interpretación y valoración crítica orientada a la conservación de los grandes textos ${ }^{7}$, una concepción de la gramática que subsume lo que hoy consideramos como tal en los estudios literarios. Pero esa concepción abarcadora de la Gramática, que se establece en el mundo greco-romano y persiste en la tradición humanística con escasas variaciones, no impide que se cree también en su seno una tradición más específica de gramática técnica (la correspondiente a la primera de las partes señaladas por Andrés), que se muestra ya en la obra de Dionisio de Tracia y de algún modo es considerada, también por Andrés, como lo básico de la Gramática:

Los griegos fueron los primeros que pensaron en hacer investigaciones sobre la constitución de las palabras y la construcción de la oración, sobre las gracias y los vicios de la dicción y sobre otros puntos semejantes, y los griegos, en suma, fueron los primeros gramáticos (Andrés: III, 479).

Es sabido que las gramáticas técnicas, al igual que los tratados de Retórica y Poética, son descripciones del funcionamiento de las lenguas, es decir, téchnes, construidas con carácter prescriptivo porque están orientadas al aprendizaje y buen uso de éstas, además de funcionar como instrumento auxiliar en la tarea filológica. Estas gramáticas ocupan, desde la Antigüedad, un espacio importante en la educación y son, en lo que se refiere a la extensión del objeto de estudio, más acordes con las gramáticas actuales. Cabe recordar que la actividad filológica desarrollada en los siglos XV y XVI para la recuperación de la producción cultural de los antiguos muestra sobradamente los dos niveles de intervención gramatical mencionados: se elaboran, por una parte, numerosas gramáticas técnicas de las lenguas antiguas ( $y$, por otros motivos, de las vulgares) $y$, por otra parte, se realizan trabajos 
de edición, traducción, comentarios y crítica que estarían comprendidos en la acepción más amplia del concepto de Gramática.

Andrés recoge, pues, en su presentación de la disciplina toda esa tradición, porque sitúa dentro de la gramática tanto lo lingüístico como lo literario y porque, sin embargo, divide desde el principio y separa luego en tres capítulos distintos la gramática técnica, la exegética y la crítica. Como neoclásico que es, se sitúa todavía, por su formación y por su actividad en el campo de las Buenas Letras, en esa tradición gramatical que no establece límites precisos entre cultivo esmerado de la lengua, estudio del funcionamiento de ésta y estudio de su literatura (por eso tampoco quería alejar la Gramática de la Elocuencia y la Poesía); aunque, al mismo tiempo, conocedor de los diferentes productos elaborados en el seno de la disciplina muestra que hay ya otras concepciones de la gramática.

Un segundo aspecto destacable en las ideas de Andrés acerca de la gramática se observa en su definición de la gramática técnica, porque cuando podría haber restringido más esta segunda acepción del término, en la línea de la posición dominante en su tiempo, amplía, por el contrario, su espacio, ahora incluso más de lo que exige la tradición:

Los antiguos gramáticos no se ceñían a la estrechez de las combinaciones gramaticales, sino que comprehendían toda la parte técnica de las artes del decir; y abrazaban en sus preceptos la Gramática, la Retórica y la Poética. Nosotros tomaremos en esta extensión la Gramática técnica, y aun comprehenderemos en ella no sólo la parte preceptiva y verdaderamente técnica, que sirve para el uso, sino también la que, contribuyendo a la inteligencia y explicación de las palabras, puede tal vez decirse más justamente exegética (Andrés: III, 493).

El autor ha partido de que la gramática técnica se ocupa "del buen modo de escribir y de hablar" y entiende que ese cometido exige incluir en ella los preceptos retóricos y poéticos en lugar de limitarse a la explicación de las "combinaciones gramaticales" (como han hecho otros, antes y en su tiempo, podríamos añadir). Andrés se ampara aquí de nuevo en la autoridad de los antiguos, aunque podría haber recurrido a ellos para defender justamente lo contrario, ya que son ellos los que establecieron la Gramática, la Retórica y la Poética como disciplinas diferenciadas y no es inusual que sus gramáticas sean consecuentes con esa separación. Pero es igualmente cierto que los límites entre esas disciplinas pronto se mostraron inestables (algo que ya advierte Quintiliano ${ }^{8}$ y que es constatable en diversos autores y obras ${ }^{9}$ ) porque todas son téchnes de la palabra. La tradición no obliga, pues, al autor en ningún sentido, por lo que podemos interpretar su actitud abarcadora como una preferencia

8 Quintiliano trata el problema de la frontera entre las disciplinas gramatical y retórica y entre los profesionales dedicados a ellas y señala que el gramático debe enseñar la corrección en el hablar y escribir (recte loquendi) y la interpretación de los poetas (poetarum enarationem), pero que el joven debe pasar a continuación al retórico sin esperar a aprender a declamar o hacer ejercicios que ya corresponden a éste. Cfr. Quintiliano: Instituciones oratorias, trad. de Ignacio Rodríguez y Pedro Sandier. Madrid, 1916, tomo I, págs. 65-68.

9 Murphy señala que la tendencia más antigua es a mantener separadas las disciplinas, pero considera el Ars Poética de Horacio como obra gramatical (como extensiön de la enarratio poetarum) y señala que el Ars Maior de Donato es la primera incursión de la gramática en el área de los schemata y los tropoi, reservada hasta entonces a la Retórica, algo que continuará en la Edad Media. Cfr. Murphy, J.J. (1974): La Retórica en la Edad Media. Historia de la teoría de la Retórica desde San Agustín hasta el Renacimiento, trad. Guillermo Hirata Vaquera. México, FCE, 1986, págs. $42-45$ y 99 . 
personal frente a opciones más restrictivas. Y podríamos decir que, si en esto Andrés se aleja de la concepción más moderna de la Gramática, se está aproximando, al mismo tiempo, a una consideración de ésta como suma de estudios sobre el lenguaje que llevaría a hacer coincidir la disciplina con lo que denominamos Lingüística en nuestro tiempo. Y en este sentido, Andrés resulta más moderno, no porque la Lingüística haya acogido en su seno las antiguas disciplinas retórica y poética, pero sí porque buena parte de los contenidos de éstas (mucho de lo que hoy es Análisis del Discurso) se ha reconocido como objeto de la ciencia del lenguaje.

La inclusión de los diccionarios en la parte de la Gramática técnica, tal como se apunta también en la presentación transcrita, supone más de lo mismo y confirma esa aproximación del concepto de gramática técnica de Andrés a nuestro concepto de lingüística, ya que, mientras el autor sugiere alguna posible reticencia a esa inclusión (el que su finalidad no sea la de prescribir el modo de usar la lengua) y se ve obligado a resaltar su carácter de instrumento para la exégesis o interpretación de los textos, hoy estas obras se insertan con naturalidad en el ámbito de la Lingüística Aplicada.

Cabe añadir que esas opciones de inclusión de las obras retóricas y de los diccionarios dentro de la Gramática se ratifican en los epígrafes que aparecen a lo largo del capítulo (Gramáticos griegos, Diccionarios griegos, Retóricos griegos, Gramáticos latinos, Retóricos latinos, etc.), e incluso, que en el recorrido por esos diferentes tipos de obras, el autor señala en ocasiones que tienen mayor interés los diccionarios o las retóricas que las gramáticas ${ }^{10}$.

Un tercer aspecto destacable en el concepto de gramática manejado por Andrés se evidencia ya en lo dicho hasta aquí: es la concepción de la gramática como arte frente al carácter de episteme o ciencia que le atribuyen otros. También aquí se sitúa el autor en la concepción antigua en la que tanto la Gramática como la Retórica son, como se ha señalado, artes del discurso, es decir, saberes prácticos que parten de la observación de los grandes textos (orales y escritos), deducen las leyes que rigen su construcción y, en consecuencia, prescriben los pasos que deben seguirse para producirlos. Es sabido que esa concepción práctica de la gramática perdura en la historia hasta nuestros días y está en la base de la elaboración de las gramáticas normativas que sirven para la enseñanza y el aprendizaje de las lenguas maternas o extranjeras, pero que no es ésta la vía que hoy se considera más relevante, o más central, en la investigación sobre el lenguaje, en cuanto que no es la que ha llevado a la constitución de una Lingüística científica. Son, por el contrario, las gramáticas filosóficas, especulativas o razonadas aparecidas en diferentes momentos (las que, como veremos, menos interesan a Andrés) las que conforman una línea de teorización sobre el lenguaje y/o las lenguas que se ha visto como precursora de las gramáticas formales del siglo XX, además de resultar una contribución esencial para el asentamiento del carácter científico de la disciplina lingüística" ${ }^{11}$.

10 Así, atribuye mayor utilidad a los diccionarios griegos que a las gramáticas del mismo tiempo y más mérito a las retóricas griegas y latinas que a ninguna otra obra (Andrés: III, 497-500).

11 Jesús Tusón presenta estas dos corrientes, teórica y práctica, como eje de su historia de la lingüística (Cfr. Tusón, J.: Aproximación a la historia de la lingüística. Barcelona, Teide, 1982, pág. 15), resaltando, en sentido contrario al de Andrés, la importancia de la corriente teórica y siguiendo en esto el camino transitado por Chomsky con la reivindicación de la gramática de Port-Royal (Cfr. Chomsky, N. (1966): Lingüística cartesiana. Madrid, Gredos, 1969. 
La apuesta de Andrés por el arte gramatical contrasta con la actitud de otros autores de su tiempo, y particularmente con la de los enciclopedistas franceses, quienes, asumiendo la tradición filosófica de la gramática francesa (establecida firmemente en Port-Royal), definen la gramática, poco antes que él, como "la science de la parole prononcée ou écrite" y señalan que su fundamento está en la Lógica, porque, independientemente de las diferencias entre las lenguas, todas tienen mucho en común, ya que común es el proceder del espíritu humano y el lenguaje es reflejo del pensamiento. Esto les lleva a distinguir dos tipos de principios gramaticales: los de una verdad inmutable, comunes a todos, que constituyen la Gramática General, una ciencia ("parce qu'elle n'a pour objet que la speculation raisonnée des principes immuables et géneraux de la parole prononcée ou écrite dans toutes les langues") y los adoptados por unos hablantes en particular, que pueden cambiar, y son objeto de las diversas gramáticas particulares, unas artes ("l'art d'appliquer aux principes inmuables et generaux de la parole prononcée ou écrite, les institutions arbitraires et usuelles d'une langue particuliere") (Diderot y D'Alembert: XV, G 104-105). Los enciclopedistas no creen que haya que separar el estudio de la Gramática General y las gramáticas particulares, pero creen que hay que distinguir una de otra, asignando a cada una su objeto, marcando sus límites y determinando sus diferencias, y este planteamiento, emergente en el siglo XVIII (aunque con fundamentos muy anteriores), es el que llega, consolidado, a nuestro tiempo, establece la distinción entre Lingüística General y lingüísticas particulares y da al traste finalmente con la concepción de los estudios lingüísticos como arte, dominante en los periodos clásicos.

\section{La historia de la Gramática}

Andrés construye, en el capítulo dedicado a la Gramática técnica, una historia de ésta que puede entenderse, con criterios actuales, como una historia de la Lingüística, pues, como ya se ha expuesto, el autor se refiere tanto a gramáticas, como a retóricas y diccionarios, e incluso, en menor medida, a otro tipo de estudios y reflexiones acerca del lenguaje. Pero su contribución a la Historiografia lingǘstica no se limita a lo que se puede encontrar en ese lugar específico, ya que ésta se completa con los datos y valoraciones que se insertan en partes más generales de la obra, particularmente en el volumen primero y en el capítulo I de la Gramática. En lo que sigue resumiré, en primer lugar, la historia de la Lingüística que aparece en el capítulo dedicado a la Gramática técnica; anotaré, después, algunas reflexiones sobre este mismo asunto que se pueden encontrar en otras partes de la obra; y comentaré, finalmente, los aspectos más destacables de ese material.

En el capitulo de la Gramática técnica, el autor comienza diciendo que ésta empezó en Grecia como Gramatística, arte de leer y escribir, porque el paso previo a la producción de literatura fue la conformación de los sistemas de escritura y su perfeccionamiento. Recoge al respecto "la opinión más común" de que tanto los caracteres hebreos como los griegos proceden de los fenicios, y da cuenta de una serie de libros escritos en Grecia y en Roma sobre las letras o la puntuación y de cómo esa tradición continuó con otros autores. Incluye después en la Gramatística, junto a lo que hoy constituye la Ortografia, la Paleografia, el arte de enseñar a hablar a los mudos y la Calografía. En lo referido a la Paleografía griega cita los trabajos de Montfaucon; los de Pluche, en la francesa; los de Burriel y Terreros, en la española; y las investigaciones de los benedictinos sobre los alfabetos de otras naciones. En cuanto al arte de enseñar a hablar a los mudos, de moda en su tiempo según dice, atribuye 
su invención al benedictino Pedro Ponce (siglo XVI), a Juan Pablo Benet el haberlo dado a conocer y al Abate L'Epée el haberlo perfeccionado en el siglo XVIII.

Después de la Gramatística comienza con la (otra) Gramática, exponiendo que, aunque otros griegos ya habían tratado algunos aspectos de ésta, el padre de la disciplina es Aristóteles, quien distingue tres partes en la oración, mientras los estoicos aumentaron las partes a cuatro o cinco y otros reconocieron ocho; y que, habiéndose perdido otras obras antiguas, tenemos, sin embargo, la de Dionisio de Tracia (discípulo del reconocidísimo Aristarco), la más perfecta y estimada de aquéllas, y algunas posteriores, recogidas en varios volúmenes, entre las que se han destacado las de Apolonio Díscolo y su hijo Herodiano. Pero encuentra Andrés más útiles que esos escritos los diccionarios coetáneos (de los que cita bastantes), por dar noticia, entre otras cosas, sobre los dialectos griegos, aunque en los etimológicos observe derivaciones extrañas; y todavía concede mayor mérito a las retóricas griegas, subrayando el valor de la Retórica y la Poética de Aristóteles y de las obras de Demetrio, Dionisio de Halicarnaso, Hermógenes y Longino. Entre los gramáticos romanos, señala a Varrón como el más antiguo, docto y enciclopédico, se refiere a varias colecciones de gramáticas y de fragmentos y concluye que Donato y Prisciano son los más memorables, y que los posteriores, como Alcuino, se limitan a copiarles; advierte, además, que en ese tiempo los latinos no elaboran diccionarios y que suplen esta carencia con muchos escritos de etimologías, de Varrón, San Isidoro y otros; y elogia por encima de todo su retórica, y muy particularmente a Cicerón y Quintiliano.

A continuación habla de los escritores de gramáticas y diccionarios griegos y latinos desde los tiempos en que "empezó a restablecerse la extinguida literatura", los que condujeron a la moderna inteligencia del helenismo y la latinidad; elogia, entre los griegos, los comentarios de Budé y el diccionario de Roberto Estéfano; cita, entre los latinos, las Elegancias de Valla, y las obras de Nebrija, Escalígero, Manuel Álvarez, Francisco Sánchez de las Brozas, Vossio y Sciopio, y a diversos autores de diccionarios; y concluye que las gramáticas latina y griega han sido mejor tratadas por los modernos que por los antiguos. Considera después las gramáticas, diccionarios y otros textos relativos a las lenguas vulgares, elaborados también a partir del siglo XV: los primeros (anteriores a esa fecha), los de la lengua provenzal (Donato provenzal y Arte Poética de Vidal de Besalú); luego, los del castellano (Gramática castellana de Nebrija, diccionarios de éste con Alfonso de Palencia, Diálogo de la lengua - presentado como de autor anónimo-, Covarrubias y Gramática y Diccionario de la Academia), alemán (Gottsched, Kramer, Junker), inglés (el diccionario de Johnson) italiano (Bembo, Buommattei, Mambelli, y el diccionario de la Academia de Crusca, entre otros, y una obra de su tiempo, el Ensayo sobre la lengua italiana de Cesarotti) y francés (enumeración rápida de obras que da por conocidas, como Port-Royal, elogio de los Sinónimos de Girad y los Tropos de Marsais y Condillac. Finalmente, conectando con la única gramática filosófica francesa a la que dedica dos líneas, la de Condillac, y bajo el epígrafe de "Gramática universal", señala que el gusto filosófico se ha traspasado a distintos tipos de investigaciones sobre las lenguas (las de Brosses sobre el mecanismo de las lenguas, D'Alembert sobre la armonia de las mismas o las de Leibnitz y otros sobre la búsqueda de una lengua universal); añade que las poéticas y retóricas modernas siguen demasiado de cerca a los antiguos (aunque ve algún interés en las poéticas de Escalígero y algunos otros autores), elogia las obras de Fénelon y declara que han acarreado ventajas para la Elocuencia las de Rollin, Condillac y el Abate Arnauld y las del inglés Hugo Blair. 
En cuanto a los datos que añade Andrés a esta historia en otras partes de la obra, cabe señalar que el capítulo I del libro de la Gramática ("De la Gramática en general") presenta un enfoque de la historia de la Filología que podríamos definir como más "social". Se habla, por ejemplo, de las veinte célebres escuelas de gramática abiertas en la ciudad de Roma para la enseñanza de esta materia, de que primero los discípulos pagaban al profesor pero más tarde se destinó dinero público a este fin, de que Cicerón acudía a las lecciones de alguno de esos maestros y ni él ni el propio Julio César desdeñaban ocuparse de cuestiones gramaticales, y de cómo los gramáticos, al tener un altísimo reconocimiento, llegaron a ensoberbecerse y a despreciar a los poetas y oradores más grandes; y se introducen, además, breves justificaciones de los cambios de rumbo producidos en el devenir de la gramática (que en el capítulo de la Gramática técnica se soslayan por suficientemente tratados en otros lugares), como la alusión a que antes de la decadencia medieval se había introducido entre los griegos y romanos "un bárbaro y rústico modo de hablar", o la consideración de que el entendimiento humano, acostumbrado a la inercia e inacción (medieval), no podía dar un paso si no era llevado de la mano de los escritores antiguos, y que para entender a éstos fue necesaria la elaboración de gramáticas. Por otra parte, se observa aquí en alguna ocasión un tratamiento más detallado de algunos aspectos; así ocurre, por ejemplo, cuando se habla de la gramática griega antigua, con referencias a los gramáticos de Pérgamo y Alejandría más completas que las del otro capítulo, o cuando se explica el papel de Dante, Petrarca y Bocaccio en el despunte de una nueva etapa y se pondera la importancia de su tarea de filólogos por encima de su contribución como poetas; e incluso aparecen informaciones no incluidas en el otro capítulo, como la del estudio de "lenguas exóticas" como el hebreo o el árabe, que aquí se trata con detalle sobre universidades y personas implicadas en su investigación y enseñanza. Finalmente, hay una reflexión interesante sobre la escritura china cuando Andrés se pregunta los motivos por los que fueron los griegos los primeros en reducir la lengua a un arte y no pueblos más antiguos, particularmente los asiáticos, que habían desarrollado con anterioridad culturas espléndidas; la respuesta es que los chinos, por la complejidad de su escritura, que ha requerido siempre de ellos un gran eșfuerzo, no pudieron hasta mucho más tarde sobrepasar la fase primera de la Gramatística ${ }^{12}$.

Cabe, por fin, añadir a esta enumeración de datos aislados relativos a la historia de la Lingüística los que aporta Andrés en el volumen I, la parte más general de su obra. Las informaciones más relevantes que encontramos en esta parte se deben a la vocación universal de la mirada del autor, al hecho de que aquí se toma en consideración la literatura de los pueblos situados más allá de las fronteras de Europa. Así, encontramos cinco páginas de noticias sobre los estudios lingüísticos árabes (Andrés: I, 111-116) a los que, en general, no han prestado atención las historias de la Lingüística occidentales. Se expone ahí que los árabes construyeron su primera gramática (la de Abu Alasuadeo Duleo) cuando, con la extensión del Islam, temieron que la unión de pueblos diversos fuese en detrimento de la lengua arábiga; que hubo después numerosos gramáticos divididos en dos academias, la basorense y la cufiense; y que, entre los muchos gramáticos reconocidos, destacó Malek (en el siglo XII en la península ibérica), autor de libros muy reconocidos y comentados. También se

12 Andrés trata esta cuestión también en el volumen primero, donde expone lo sorprendente que resulta que una cultura tan antigua, de cuyo desarrollo y continuidad se tiene puntual noticia, no haya conseguido avanzar más en las Ciencias y en las Letras (Andrés: I, 20-23). 
refiere elogiosamente a los numerosos diccionarios elaborados a partir del primer siglo de la hégira, alguno muy voluminoso, varios referidos a materias específicas y algunos bilingües (arábigo-hebraicos, arábigo-griegos, arábigo-latinos y arábigo-españoles); y a las retóricas, entre las que concede el más alto valor al libro de Assiutheo El prado florido y a la obra del persa Alsekaki. En otra escala, resultan dignas de atención las referencias a la cultura hindú y a la lengua sánscrita, en un momento en que los europeos tenían ya abundantes noticias acerca de éstas; Andrés muestra en detalle el debate intelectual de su tiempo entre los más proclives al reconocimiento de la antigüedad y relevancia de esa cultura y los más cautos (él mismo) ante las muchas incertidumbres aún no despejadas, todo ello en vísperas de la constatación de la relación del sánscrito con las lenguas griega y latina que había de afectar sustancialmente a la evolución de la Lingüística ${ }^{13}$. Finalmente, Andrés aporta en este volumen una interesante reflexión sobre la antigüedad de las lenguas vulgares europeas (alemán y lenguas escandinavas, inglés, francés y español, principalmente) (Andrés: I, 218 y sigs.) y sobre la situación de coexistencia diglósica que afectó al latín y a las lenguas vulgares europeas durante bastante tiempo (Andrés: I, 218-226), y analiza con sagacidad, en notas diseminadas en diversos lugares, no sólo la evolución de las lenguas (con una reflexión sobre la entrada de extranjerismos en la que manifiesta una postura muy abierta (Andrés: I, 408 y III, 221-222) sino también la evolución del lenguaje en su desarrollo histórico ${ }^{14}$.

Pasando ya de la revisión de los datos al comentario y valoración de éstos, cabe decir, en primer lugar, que Andrés concibe la historia como devenir que implica "progreso" (es la palabra que utiliza en el título para referirse a la evolución de las diferentes materias), es decir, como evolución que conduce a resultados más satisfactorios, aunque puedan producirse en el camino retrocesos coyunturales (la Edad Media). Y la fragmentación del tiempo que propone, visible con particular claridad en el índice del volumen primero de la obra (véase el anexo II), responde, en general, a esa concepción, muy acorde, por lo demás, con la mentalidad dieciochesca. Es esa perspectiva, la de la cultura neoclásica en la que el autor se inserta, la que le lleva a dedicar cinco de los dieciséis capítulos del primer volumen a la literatura grecolatina, a desdibujar como etapa, excepto en lo que se refiere a la constatación de la decadencia, los "tiempos bajos" de la Edad Media, y a mostrar una recuperación del orden de las cosas a partir del siglo XV (cuando los italianos sientan las bases de la restauración de la cultura antigua) ${ }^{15}$, distinguiendo ya en capítulos separados los avances realizados en los siglos XVI, XVII y XVIII, que juntos configuran para él la nueva etapa de progreso.

Sorprende, sin embargo, en ese contexto, que el jesuita dedique cuatro capítulos a la contribución de los árabes mientras sólo dedica uno a la literatura eclesiástica de la Edad Antigua (desde los orígenes de ésta hasta una explicación minuciosa de los motivos de su decadencia en el siglo VI, que no consiguen paliar personalidades tan singulares como San Gregorio y San Isidoro). Se trata, sin duda, de una apuesta personal del erudito que le lleva a polemizar con quienes no valoran esa contribución, o incluso atribuyen a ese pueblo

13 Aunque esa relación del sánscrito con las lenguas clásicas europeas ya había sido apuntada, es en 1786 cuando el juez de Calcuta William Jones publica el texto que había de alertar definitivamente a los lingüistas y abrir la investigación de la Lingüística histórica y comparada.

14 Véase, por ejemplo, la página dedicada a los cambios de estilo de lenguaje que se observan en el siglo XVIII (Andrés: I, 365).

15 El autor rebate una idea que presenta como dominante en su tiempo: la de que es la llegada a Italia de los griegos desplazados por la toma de Constantinopla lo que pone en marcha el resurgir cultural (Andrés: I, 270-303). 
alguna responsabilidad en el prolongado retroceso de la cultura europea. Andrés rebate esas posiciones con un análisis minucioso de los progresos realizados por los árabes en el estudio de las Ciencias, de su labor, previa y paralela, de conservación y transmisión de la cultura grecolatina antigua y del ejemplo que ofrecieron con su cultivo de las Bellas Letras (aunque en este último sector de la literatura no alcanzaran el altísimo nivel obtenido en los anteriores). En toda esta parte se encuentra el material más original de su historia de la Lingüística, ya que ha sido, y es, infrecuente la atención de los historiadores de la Lingüística occidentales a los estudios realizados en otras latitudes, y Andrés no sólo lo hace sino que se aplica a ello con particular dedicación ${ }^{16}$.

La misma concepción y fragmentación de la historia que se observa en el volumen primero sigue percibiéndose con nitidez en el libro dedicado a la Gramática, aunque las etapas históricas no sean aquí tan explícitas (porque los epígrafes que dividen los capítulos de la Gramática General y de la Gramática Técnica no se refieren ya a siglos o periodos sino a algún tipo de obras). Pero no es necesario, creo, resaltar que son las obras antiguas y las que recuperan esa tradición en el Renacimiento las que ocupan más espacio y obtienen una valoración más alta en la Historia de la Lingüística de Andrés.

Un segundo aspecto significativo es lo que se refiere a las fuentes citadas por el autor para la elaboración de su historia de la gramática. Destaca al respecto, en primer lugar, lo que es común en toda la obra, la declaración minuciosa de las fuentes y la ausencia de cualquier ocultamiento, y se observa, además, alguna diferencia entre las mencionadas en la construcción de las partes dedicadas a las Ciencias, donde el autor declara que se sirve de historias de ciencias particulares y las cita y valora llegando a afirmar de algunas que han resultado una ayuda decisiva para poder presentar los progresos realizados en esa área del saber (Andrés: I, 11), y las utilizadas en el tratamiento de las Buenas Letras. En este caso, el autor muestra un conocimiento directo de los clásicos, antiguos y renacentistas, y de las obras más relevantes de su tiempo, incluso de las menos acordes con su posición intelectual, y advierte, además, que las muchas divergencias que observa en el parecer de diversos autores le han obligado a leer con atención muchos textos para formarse una opinión ${ }^{17}$. En lo que concierne a la historia de la Gramática, declara que sigue a Dionisio de Halicarnaso, Quintiliano y Prisciano en lo referido a las obras antiguas, y cuando cita historias modernas (por ejemplo, la de Tiraboschi, la más importante de las letras italianas) parece hacerlo más con carácter informativo, o para mostrar acuerdo o desacuerdo con autores significados que para trasladar los datos elaborados por éstos; y únicamente al tratar de la gramática árabe busca un apoyo más firme en una Historia de las Antigüedades arábigas ${ }^{18}$ y en el catálogo de Casiri de los códices árabes de El Escorial, entre otros. Por lo demás, el amplio conoci-

16 Andrés justifica el dedicar una mayor extensión a lo árabe precisamente porque entiende que otras cosas son más sabidas mientras que persiste la ignorancia y el error acerca del mérito de esta literatura y de su importancia en la potenciación de la literatura moderna europea (Andrés: 1, 10).

17 "Para esto [para formarse una idea clara de los progresos de las Buenas Letras] es preciso una exacta y justa crítica de los escritores y de las obras que han tenido en ella alguna parte; y así, he querido leerlas más de una vez y formar por mí mismo el juicio sin sujetarme al de otros, como se hace con mucha frecuencia. He visto en algunos autores tan poca sinceridad y en otros tanta ignorancia; he encontrado tan discordes en sus juicios aun a los jueces más ilustrados, que he creído no poder tomar más seguro partido que el de formar mi juicio leyendo con cuidado las mismas obras y manifestarlo libremente al público" (Andrés: I, I1).

18 El autor, Schamseddin Alansareo, se cita, junto al título de la obra, en el primer párrafo de esta parte. 
miento de las obras que muestra el autor se observa en el carácter mismo de su texto, que, si es abundante en datos, no lo es menos en la manifestación de juicios, que el autor razona y que a menudo ofrecen una postura propia en relación con aspectos polémicos.

Un tercer elemento, muy sustancial en la historia de la Lingüística de Andrés y ya enunciado, es su decantación a favor de las gramáticas prácticas frente a las teóricas o filosóficas. Esta posición se muestra con nitidez no sólo en las definiciones de la Gramática que adopta (lo que ya hemos hecho notar en el epígrafe anterior), sino también en la historia que elabora para explicar el desarrollo de la disciplina: mientras Andrés reconstruye y valora con bastante detalle la historia de las obras gramaticales de carácter práctico, cita muy de pasada todas las gramáticas teóricas o filosóficas, y no manifiesta ningún entusiasmo ante éstas.

Ese tratamiento de la historia se observa muy concretamente en algunos hechos. En primer lugar, en la ausencia de datos o valoraciones de las gramáticas especulativas de los modistae medievales, una omisión que podría explicarse por el rechazo de la escolástica que muestra el autor en el libro dedicado a la Filosofia entre otros lugares (Andrés: V, 425 y sigs.). Podríamos pensar que en este caso no se está rechazando el carácter especulativo de las gramáticas medievales sino un sistema filosófico y una actitud intelectual propias del Medievo que el autor considera afortunadamente superadas. Pero un segundo caso indica que hay algo más: respecto a las gramáticas razonadas del siglo XVI, el autor muestra una actitud respetuosa, y aun elogiosa en alguna ocasión, pero siempre acompañada de alguna crítica. Así ocurre cuando cita los trece libros de J.C. Escalígero sobre las causas de la lengua latina diciendo que este autor "tuvo la gloria de ser el primero entre los modernos que introdujo la Filosofía en la Gramática, aunque junta con no pocas cosas o enteramente inútiles o demasiado sutiles" (Andrés: III, 501); y lo mismo sucede con su juicio sobre Sánchez de las Brozas y otros cuando dice:

No áridos y estériles preceptos, y a veces aun falsos y erróneos, como hacían los antiguos, sino doctas observaciones y reglas justas, fundadas en los buenos ejemplos y en la razón, constituyen el mérito de estos gramáticos, de los cuales, por ventura, Sánchez y Sciopio pecan alguna vez en quererse sujetar sobrado a la razón, en una materia que en gran parte depende más del uso y del ejemplo de los buenos autores que de la razón (Andrés: III, $502)$.

Y se refiere también a las gramáticas filosóficas cuando habla de las de su tiempo, atribuyendo a los franceses la introducción del espíritu filosófico. Y aquí se limita a enumerar algunas de esas obras (la de Port-Royal entre otras) señalando que no hablará de ellas, a algún lacónico elogio, a decir del Arte de hablar de Condillac que es "una Gramática filosófica donde tal vez parecerá que se hace sobrado uso de la Metafísica y que es excesiva la gana de filosofar" y a situar, sin mayor comentario, dentro de ese gusto filosófico algunas otras investigaciones sobre las lenguas (Andrés: III, 505-506). La actitud de Andrés en todos los casos señalados no ofrece duda: mientras valora toda la tradición de las gramáticas prácticas, muestra una permanente reserva ante las teóricas, razonadas o filosóficas, las que, por otra parte, él mismo presenta como las más significativas de su tiempo.

Podemos relacionar esa actitud con algunos testimonios que hablan de la escasa fortuna que tuvo la gramática filosófica en España, pese a la prestigiadísima obra pionera de Sánchez de las Brozas. Así, Gregorio Mayans, amigo y referente intelectual del Abate Andrés 
en su etapa de Gandia ${ }^{19}$, señalaba en 1768 que la doctrina del Brocense: "lució en España como un relámpago, que presto se apagó y dejó de alumbrar, hasta que Gaspar Sciopio tuvo la dicha de hallarla entre las cenizas del olvido, i la comunicó a todas las naciones que deseavan ser bien instruidas"; y añade que los franceses e italianos, que siguieron la doctrina del Brocense, han compuesto gramáticas "más estendidas i cumplidas, que las antecedentes, $i$ por ellas se enseña con grandes ventajas"20. También Lázaro Carreter ${ }^{21}$ recoge esa diferencia entre el modo en que se instaló en Francia, con Port-Royal, la gramática razonada y lo que ocurrió en España con Sánchez de las Brozas (pese a que el propio Lancelot muestra en su prólogo su deuda con éste); y advierte que, además de que aquí interesaban las gramáticas prácticas y no las razonadas, los jesuitas no usaban estas últimas (Lázaro Carreter: 154-155). Y el mismo Lázaro, aunque no se ocupa de las ideas expuestas por Andrés ${ }^{22}$, recuerda otra particular coyuntura: el carácter jansenista de Port-Royal y el hecho de que la oposición a la herejía jansenista estuviera a cargo de la Compañía de Jesús. Estas circunstancias podrían indicar que la condición de jesuita de Juan Andrés pesa en su juicio sobre las gramáticas filosóficas.

Pero, seguramente, la explicación es más sencilla. Andrés muestra en general una postura abierta y sensible al "progreso", que le conduce a un seguimiento activo de las novedades científicas de 'su tiempo (algo que se observa sobradamente en esta obra y en alguna otra publicación breve referida a cuestiones cientificas); y su condición de jesuita no le impide elogiar los escritos de Voltaire y de otros librepensadores combatidos por muchos de sus correligionarios, todo ello en una tesitura histórica propicia a la beligerancia entre lo laico y lo religioso ${ }^{23}$. Esas muestras de la personalidad del Abate invitan a pensar que sus reticencias ante las gramáticas filosóficas tienen que ver sobre todo con su formación clásica, que hace de él, en lo que se refiere a las Buenas Letras, además de un excelente conocedor de las obras antiguas y de toda la actividad restauradora del Renacimiento, un convencido humanista, defensor de la excelencia de los clásicos y de una razón que se opone a la Escolástica. Frente a unas gramáticas filosóficas (las de su tiempo y las anteriores) que conectan con el pensamiento escolástico al interrogarse sobre la relación entre lenguaje y pensamiento,

19 La amistad y el respeto mutuo que se profesan estos intelectuales está por encima de cualquier diferencia en materia religiosa y se muestra en algunas de sus cartas. Véanse la carta de Mayans y otros frägmentos transcritos en el estudio preliminar de la actual edición de Andrés (Andrés: I, XXX-XXXII).

20 Cfr. Mayans y Siscar, Gregorio, "Idea de la gramática de la lengua latina", en Obras completas, ed. de Antonio Mestre Sanchos, Valencia, Publicaciones del Ayuntamiento de Oliva, 1986, vol V, pág. 40.

21 Lázaro Carreter, F. (1949): Las ideas lingüísticas en España durante el siglo XVIII. Barcelona, Crítica, 1985.

22 Lázaro Carreter no analiza la contribución de Andrés a la historiografia lingüística; sólo cita la defensa que hace el Abate del uso del latín (acorde con los estatutos y las prácticas seguidas por su orden), un aspecto en el que también discreparía con la posición de Port Royal. Creo, no obstante, que se trata de un asunto menor: el Abate, aunque defienda puntualmente el uso del latín, escribe su obra en italiano.

23 El talante abierto, sosegado y tolerante de Andrés fue destacado ya por sus oponentes en la polémica que mantuvo con Tiraboschi en defensa de la cultura española, y lo muestra en su obra cuando explica su postura respecto a los autores "libertinos" e "irreligiosos" de su tiempo: "considerando la religión y las letras como dos cosas distintas en un todo, veo que puede un filósofo estar abandonado de Dios según los deseos de su corazón y tener, sin embargo, sutil ingenio y fino discernimiento y pensar justa y verdaderamente en las materias literarias" (Andrés: I, 359-360). Menéndez Pelayo también destacó entre los méritos de Andrés ese talante que le llevó a considerar por primera vez en la historia de la literatura a los pueblos del remoto Oriente y del Norte de Europa, y a introducir en su obra relaciones y juicios novedosos. Cfr. Menéndez Pelayo, M.: Historia de las ideas estéticas' en España, ed. Rafael de Balbín. Madrid, CSIC, 1974, págs. 1318-1328. 
Andrés cree que la gramática tiene que ver con el uso y con los ejemplos que se ofrecen para ese uso y que otras especulaciones no contribuyen a mejorar la función asignada al arte gramatical.

Finalmente, cabe destacar el acierto que supone la inclusión de la Gramatística, la reflexión sobre el código escrito, como parte de la historia de los estudios sobre el lenguaje. La referencia a este aspecto no es una originalidad de Andrés, pues hay en el siglo XVIII, además de una atracción por el tema de los orígenes del lenguaje (que llegaría a ser censurada por constituir especulaciones que no podían probarse empíricamente), un abierto interés por el origen y la evolución de la escritura y por la relación de ésta con la oralidad, algo que no resulta extraño en un momento de evolución significativa de la lengua escrita en relación con la creación de la ciencia moderna ${ }^{24}$. Esa sensibilidad ante el fenómeno de la escritura se pierde después, con el desembarco de los formalismos en el ámbito de la Lingüística, y sólo se recupera recientemente, después de que investigaciones desarrolladas en el seno de otras disciplinas hayan mostrado la importancia cultural y lingüística de la evolución del binomio oralidad/escritura ${ }^{25}$.

La exposición de Andrés sobre la Gramatística, sitúa la Paleografía en su lugar natural, la Linguística, un lugar al que todavía hoy no se ha restituido plenamente esta disciplina después de ser expulsada (por la vía del silenciamiento) y ser considerada, abusivamente, como mero instrumento auxiliar de los historiadores. Apartada de la Lingüística, como si no tuviera nada que ver con el lenguaje, sufrió peor suerte que la Fonética cuando la Lingüística dominante en el siglo XX decidió que no importaba la realidad física del lenguaje. Si la Fonética nunca pudo ser expulsada del todo, porque es difícil negar la realidad sonora del lenguaje, y menos cuando el desarrollo tecnológico permitía por primera vez un examen riguroso de ese material, la realidad física de la escritura era más fácil de soslayar, e incluso se podía renegar de ella (de lo físico y lo no físico de la escritura) porque los textos escritos durante mucho tiempo casi habían suplantado al lenguaje oral como objeto de estudio. Con mayor motivo aún (dentro de esa lógica), quedaron fuera de la atención de los lingüistas las manifestaciones más antiguas de la escritura.

Frente a todo esto, la opción de Andrés, y de sus coetáneos, parece más sensata, porque las escrituras antiguas son productos del lenguaje, que lo muestran y han incidido en él, tal como advirtió Humboldt ${ }^{26}$. Separar las palabras o no separarlas, el uso de abreviaturas, la

\footnotetext{
24 Una muestra original y muy significativa de tratamiento intenso y sistemático de este problema se encuentra en la obra de Thomas Sheridan, un ensayo sobre los problemas de mala pronunciación en la lectura en voz alta ocasionados por las insuficiencias del código escrito y por una mala enseñanza de la lectura (Cfr. Sheridan, T.(1762): A Course of Lectures on Elocution. Nueva York, Benjamin Blom, Inc., 1968); y una excelente síntesis de la historia de la escritura se puede ver en una de las "lecciones" de Hugo Blair (Cfr. Blair, H. (1783): Lecciones sobre la Retórica y las Bellas Letras, trad. De J.L. Munárriz, Madrid, 1817, vol. I, págs. 156-171). Andrés no cita la obra de Sheridan, pero elogia la de Blair, mucho más conocida, tanto en su tiempo como posteriormente.

25 A ello me he referido en Abascal, Ma Dolores (2004), La teoria de la oralidad, anejo XLIX de Analecta Malacitana, Universiđad de Málaga, págs. 22-43.

26 Humboldt reflexiona sobre la influencia de la escritura alfabética en el lenguaje y las lenguas (en la pronunciación de éstas, en su evolución, etc.). Aunque no se refiere explícitamente a la Paleografia, se interesa por diferentes sistemas de escritura y por el modo en que éstos se relacionan con la lengua y el pensamiento de un pueblo), y advierte que "no es posible entender de manera completa la naturaleza del lenguaje si no se investiga al mismo tiempo su conexión con la escritura alfabética". Cfr. Humboldt, Wilhelm von, "Sobre la escritura alfabética y su conexión con la estructura de las lenguas", en Escritos sobre el lenguaje, edición y trad. de A. Sánchez Pascual, prólogo de José Ma Valverde, Madrid, Península, 1991, pág. 102.
} 
puntuación o la distinción de mayúsculas y minúsculas en una escritura, entre otros rasgos, muestran, sin duda, percepciones distintas de los elementos del lenguaje; y el análisis de las diferencias que ofrecen los testimonios escritos de diferentes tiempos y lugares aporta datos muy relevantes sobre el lenguaje y las lenguas y sobre el modo en que uno y otras han evolucionado.

E igualmente resulta acertada la atención de Andrés al lenguaje de los sordomudos, el sistema sustitutivo del lenguaje humano basado en el gesto, y su inclusión en la Gramatística en tanto que código sustitutivo del alfabeto. La creación de ese código y su evolución, la mezcla que presenta de naturaleza y convención, de iconos y signos abstractos, y otros aspectos de su especificidad dicen mucho acerca de lo esencial del lenguaje humano, y así lo ha comprendido la Lingüística de nuestro tiempo cuando incluye en su ámbito lo referido a las lenguas de $\operatorname{signos}^{27}$.

En fin, se ha de ponderar el interés del pensamiento lingüístico de Andrés no sólo en relación con la gramática, a la que nos hemos referido de manera central en este artículo. Sus ideas sobre el lenguaje y su estudio ayudan a entender un momento histórico de cambios y adaptaciones en todos los órdenes, porque en su exposición se encuentran certidumbres a la vez que debates abiertos y cautelas (de Andrés y de otros) muy decidores respecto al estado de los estudios lingüisticos y a la evolución de éstos que se avecinaba (está la incógnita del sánscrito, la opción por una Lingüística más teórica y científica, la situación crítica del latín como lengua universal de cultura, la crisis del estilo retórico, etc.). Además, Andrés muestra unas construcciones y puntos de vista que, aunque a veces se oponen a las posiciones dominantes en la Lingüística actual, en algunos aspectos resultan modernos y, en otros, al menos, no han periclitado; basta recordar en relación con esto, junto a otros elementos ya comentados, que la selección de autores y obras que presenta en su historia de la Lingüística, en poco diverge de la que presentan los manuales actuales. Por todo ello, creo que la contribución de Juan Andrés no merece el olvido.

\section{Referencias bibliográficas}

Abascal, M. D. (2004): La teoría de la oralidad. Anejo XLIX de Analecta Malacitana, Universidad de Málaga.

Andrés, J.: Origen, progresos y estado actual de toda la literatura, ed. de Jesús García Gabaldón, Santiago Navarro y Carmen Valcárcel, dir. Pedro Aullón de Haro. Madrid, Verbum, 1997-2002, 6 vols.

Blair, H. (1783): Lecciones sobre la Retórica y las Bellas Letras, trad. de J.L. Munárriz. Madrid, 1817,4 vols.

Chomsky, N. (1966): Lingüistica cartesiana. Madrid, Gredos, 1969.

Diderot y D’Alembert (1756): Encyclopédie, ou dictionnaire raisonné, des Arts et des Métiers, ed. facsímil. Milán/ París, Franco Maria Ricci ed., 1978.

27 Creo que cabe felicitarse por la importante presencia de este campo en la Universidad de Alicante, tanto en el Área de Lingüística (que cuenta con especialistas que investigan e imparten como asignatura la Lengua de Signos) como en la Biblioteca Virtual Miguel de Cervantes, que pone materiales al alcance de la comunidad sorda y de los investigadores de otros Jugares. 
Humboldt, W. von: "Sobre la escritura alfabética y su conexión con la estructura de las lenguas". En Escritos sobre el lenguaje, ed. y trad. de A. Sánchez Pascual, prólogo de José $\mathrm{M}^{\mathrm{a}}$ Valverde. Madrid, Península, 1991, págs. 101-132.

Lázaro Carreter, Fernando (1949): Las ideas lingüisticas en España durante el siglo XVIII. Barcelona, Crítica, 1985.

Mayans y Siscar, Gregorio: "Idea de la gramática de Ia lengua latina". En Mayans y Siscar, Gregorio: Obras completas, ed. de Antonio Mestre Sanchos. Valencia, Publicaciones del Ayuntamiento de Oliva, 1986, vol V, págs. 37-67.

Menéndez Pelayo, Marcelino: Historia de las ideas estéticas en España, ed. Rafael de Balbín. Madrid, CSIC, 1974.

Murphy, James, J. (1974): La Retórica en la Edad Media. Historia de la teoría de la Retórica desde San Agustín hasta el Renacimiento, trad. Guillermo Hirata Vaquera. México, FCE, 1986.

Quintiliano: Instituciones oratorias, trad. de Ignacio Rodriguez y Pedro Sandier. Madrid, 1916.

Sheridan, Thomas (1762): A Course of Lectures on Elocution. Nueva York, Benjamin Blom, Inc., 1968.

Tusón, J. (1982): Aproximación a la historia de la lingüistica, Barcelona, Teide. 
Anexo I. Distribución de materias en Origen, progresos y estado actual de toda la literatura $^{28}$

\begin{tabular}{|c|c|c|c|c|}
\hline \multirow{12}{*}{$\begin{array}{l}\text { LITERATURA } \\
\text { Vol. I }\end{array}$} & \multirow{4}{*}{$\begin{array}{l}\text { BUENAS } \\
\text { LETRAS } \\
\text { Vols. II y III }\end{array}$} & $\begin{array}{l}\text { Poesía } \\
\text { (vol. II) }\end{array}$ & \multicolumn{2}{|c|}{$\begin{array}{l}\text { - Epica } \\
\text { - Didascálica } \\
\text { - Dramática } \\
\text { - Lírica } \\
\text { - Pequeños poemas } \\
\text { - Romances } \\
\end{array}$} \\
\hline & & $\begin{array}{l}\text { Elocuencia } \\
\text { (vol. III) }\end{array}$ & \multicolumn{2}{|l|}{$\begin{array}{l}\text { - Forense } \\
\text { - Didascálica } \\
\text { - Dialogal } \\
\text { - Epistolar } \\
\text { - Elogios } \\
\text { - Sagrada } \\
\end{array}$} \\
\hline & & $\begin{array}{l}\text { Historia } \\
\text { (vol. III) }\end{array}$ & \multicolumn{2}{|l|}{$\begin{array}{l}\text { - Historia } \\
\text { - Geografía } \\
\text { - Cronología } \\
\text { - Anticuaria }\end{array}$} \\
\hline & & $\begin{array}{l}\text { Gramática } \\
\text { (vol. III) }\end{array}$ & \multicolumn{2}{|l|}{$\begin{array}{l}\text { - Técnica } \\
\text { - Exegética } \\
\text { - Crítica }\end{array}$} \\
\hline & \multirow{8}{*}{$\begin{array}{l}\text { CIENCIAS } \\
\text { vols. IV, V, } \\
\text { VI y VII }\end{array}$} & \multirow{4}{*}{$\begin{array}{l}\text { Naturales } \\
\text { (vols. IV y V) }\end{array}$} & \multirow[t]{2}{*}{ - Matemáticas } & $\begin{array}{l}\text { Puras: } \\
\text { - Aritmética } \\
\text { - Álgebra } \\
\text { - Geometría }\end{array}$ \\
\hline & & & & $\begin{array}{l}\text { Mixtas: } \\
\text { - Mecánica } \\
\text { - Hidrostática } \\
\text { - Náutica }\end{array}$ \\
\hline & & & - Física & $\begin{array}{l}\text { - Óptica } \\
\text { - Astronomía } \\
\text { - Física } \\
\text { - Química } \\
\text { - Botánica } \\
\text { - Historia Natural } \\
\text { - Anatomía } \\
\text { - Medicina } \\
\end{array}$ \\
\hline & & & - Filosofia & $\begin{array}{l}\text { - Filosofía racional } \\
\text { - Filosofía moral } \\
\text { - Jurisprudencia }\end{array}$ \\
\hline & & \multirow{4}{*}{$\begin{array}{l}\text { Eclesiásticas } \\
\text { (vol. VI) }\end{array}$} & - Teología & \\
\hline & & & $\begin{array}{c}\text { - Ciencia } \\
\text { biblica }\end{array}$ & $\begin{array}{l}\text { - Crítica bíblica } \\
\text { - Hermenéutica } \\
\text { biblica } \\
\text { - Exegética } \\
\end{array}$ \\
\hline & & & \multicolumn{2}{|c|}{ - Historia Eclesiástica } \\
\hline & & & - Derecho Can & \\
\hline
\end{tabular}

28 Adaptación del esquema que se presenta en el estudio preliminar de la edición de Andrés (Andrés: I, LXXVI). 
Anexo II. Índice del primer volumen de Origen, progresos y estado actual de toda la literatura

\section{Tomo I}

Cap. I. Del estado de la literatura anterior a la griega

Cap. II. Del origen de la literatura griega

Cap. III. Causas de los progresos de los griegos en la literatura

Cap. IV. Estado de la literatura de los griegos

Cap. V. Literatura romana

Cap. VI. Paralelo de la literatura griega con la romana.

Cap. VII. Literatura eclesiástica

Cap. VIII. Literatura de los árabes

Cap. IX. Influencia de la literatura arábiga en la restauración de la Europa

Cap. X. Invenciones que nos han transmitido los árabes

\section{Tomo II}

Cap. XI. Influencia de los árabes en la cultura moderna de las Buenas Letras

Cap. XII. Estado de la Literatura hasta la venida de los griegos a Italia

Cap. XIII. Literatura del siglo XVI

Cap. XIV. Literatura del siglo XVII

Cap. XV. Literatura del siglo XVIII

Cap. XVI. Ulteriores adelantamientos de la literatura 